\title{
Perancangan Sistem Penjadwalan Perkuliahan dengan Algoritma Genetika Berbasis Web (Studi Kasus : Fakultas Ilmu Komputer Universitas Katolik Santo Thomas)
}

\author{
Andy Paul Harianja ${ }^{1}$, Mei Lestari Harefa ${ }^{2}$ \\ ${ }_{1,2}$ Universitas Katolik Santo Thomas Jl. Setia Budi No. 479 F Medan, 061-821016, Indonesia
}

\section{ARTICLE INFORMATION}

Received: Maret, 5, 2020

Revised: Maret, 22, 2020

Available online: April,20, 2020

\section{KEYWORDS}

algoritma genetika, penjadwalan perkuliahan, $M Y S Q L$

CORRESPONDENCE

E-mail: apharianja@gmail.com

\section{A B $\quad \mathbf{S}$ T $\mathbf{R}$ A $\mathbf{C}$ T}

\begin{abstract}
Sistem penjadwalan perkuliahan yang selama ini terjadi di Fakultas Ilmu Komputer Univeristas Katolik Santo Thomas memiliki banyak sekali kendala yang menghambat proses penyusunan jadwal perkuliahan. Sering adanya jadwal bentrok pada saat pembuatan jadwal membuat proses pembuatan jadwal tidak efisien karena banyak menghabiskan waktu. Tujuan dari penelitian ini adalah untuk menghasilkan sebuah sistem penjadwalan perkuliahan yang dapa mempermudah proses penjadwalan perkuliahan, meminimalisisr adanya ruangan ataupun jadwal bentrok dan mempermudah pencarian ruangan untuk kuliah pengganti. Sistem penjadwalan perkuliahan ini menggunakan algoritma genetika, sehingga proses penjadwalan perkuliahan dapat disusun dengan lebih mudah, cepat, dan akurat sehingga proses penyusunan jadwal perkuliahan tidak menghabiskan banyak waktu.
\end{abstract}

\section{LATAR BELAKANG}

Kesalahan-kesalahan yang terjadi pada penjadwalan perkuliahan selama ini yaitu ruangan yang digunakan bentrok, jadwal mengajar dosen bentrok ataupun jadwal mengajar yang dijadwalkan tidak sesuai dengan waktu kesediaan dosen [1], kapasitas ruangan yang dijadwalkan tidak sesuai dengan jumlah mahasiswa. Selain jadwal perkuliahan yang dilakukan sehari-hari yang jadwalnya telah ditetapkan, FIKOM juga memiliki jadwal kuliah pengganti. Kuliah pengganti akan diadakan apabila pembelajaran tidak diadakan karena dosen berhalangan misalnya rapat, ada acara di kampus, ataupun halangan lain yang membuat pembelajaran tidak diadakan, sehingga dosen dan mahasiswa akan mencari waktu untuk melaksanakan kuliah pengganti menggantikan hari tersebut[2]. Pencarian ruangan yang dilakukan selama ini yaitu pada waktu/jam kuliah pengganti mahasiswa atau dosen akan menggunakan ruangan yang kosong pada waktu/jam tersebut. Hal ini sangat tidak efisien karena jika pada hari tersebut ada banyak mata kuliah yang mengadakan kuliah pengganti sehingga ruangan tidak ada lagi yang kosong, maka kuliah pengganti mata kuliah tersebut akan dibatalkan atau diadakan di hari yang lain lagi.

Berdasarkan latar belakang masalah di atas penulis memberikan solusi yaitu perancangan sistem penjadwalan perkuliahan dengan algoritma genetika[3], [4] berbasis web. Dengan adanya sistem penjadwalan perkuliahan maka kesalahan-kesalahan yang terjadi selama ini dapat diminimalisir karena mempertimbangkan segala aspek yang mempengaruhi penjadwalan perkuliahan. Algoritma genetika yaitu teknik pencarian di dalam ilmu komputer untuk menemukan solusi yang optimal [5]. Algoritma genetik merupakan proses pencarian yang heuristik dan acak [6], [7] sehingga penekanan pemilihan operator yang digunakan sangat menentukan keberhasilan algoritma genetik dalam menemukan solusi optimum suatu masalah yang diberikan [8].

\section{METODE PENELITIAN}

Dalam menyelesaikan sebuah penelitian perlu membuat sebuah langkah dan tahapan agar penelitian tersebut sesuai dengan kebutuhan dan selesai tepat waktu [9], adapun metodologi penelitian yang dilakukan dalam penelitian ini adalah :

1. Observasi Metode Pengumpulan data dengan cara mengamati langsung sistem monitoring yang sedang berjalan di Fakultas Ilmu Komputer

2. Studi Pustaka Metode pengumpulan data dengan cara mencari referensi dari buku dan jurnal yang terkait dengan penelitian.

3. Wawancara Metode Pengumpulan data dengan cara tanya jawab kepada pihak-pihak yang berhubungan dengan penelitian.

\section{HASIL DAN PEMBAHASAN}

\section{Perancangan}

Berdasarkan gambar 1 menjelaskan bahwa pada sistem yang dibangun tersebut terdapat 3 aktor yaitu: admin, kaprodi, dan dosen. Berikut penjelasan tugas masing-masing aktor. 


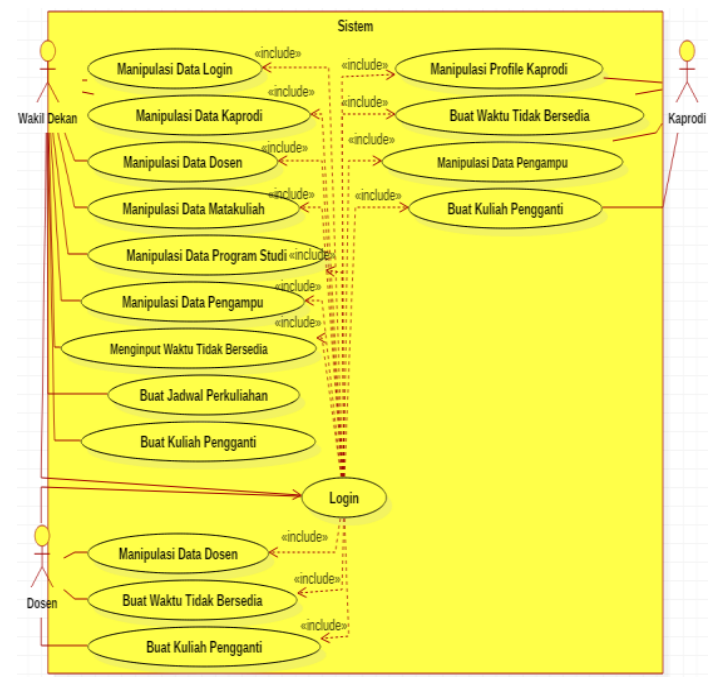

Gambar 1 Use Case Diagram Sistem Penjadwalan Perkuliahan

Gambar 2 berikut adalah rancangan menu home sebelum login. Menu home ini adalah menu yang tampil pertama pada saat mengakses sistem ini.

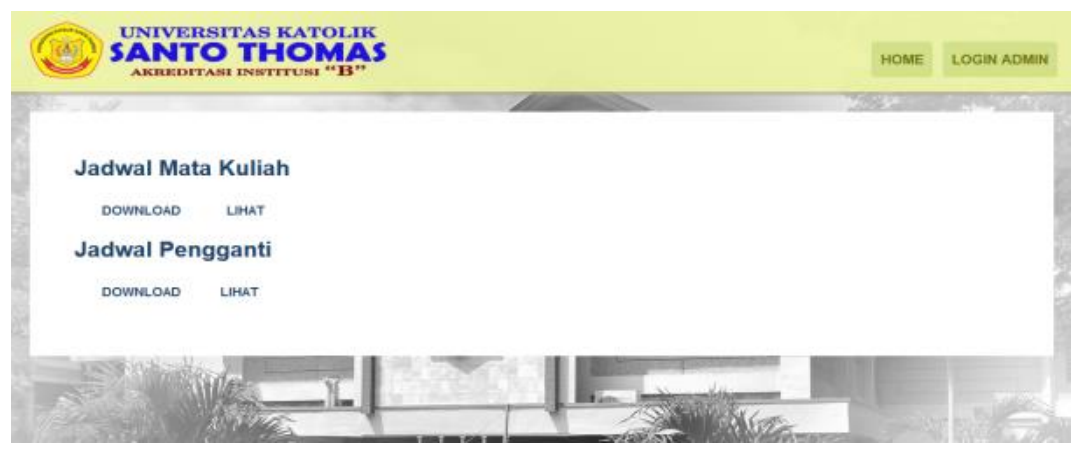

Gambar 2 Menu Home

Gambar 3 berikut adalah rancangan menu login. Menu ini berisi username dan password yang harus diisi agar dapat login ke sistem.

\section{Login Admin}

\begin{tabular}{|l|}
\hline Username \\
\hline Password \\
\hline ADMIN \\
\hline
\end{tabular}

\section{Login}

Gambar 3 Menu Login

Gambar 4 berikut adalah rancangan menu home admin. Menu ini adalah menu yang tampil pertama setelah login ke sistem. 


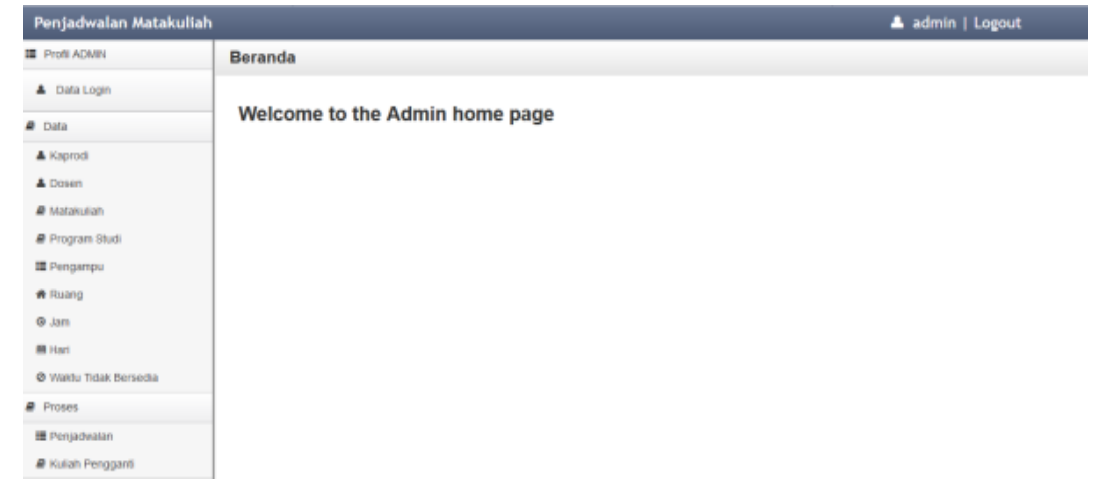

Gambar 4 Menu Home

Gambar 5 berikut adalah menu Dosen. Menu ini dapat digunakan admin untuk memanipulasi data Dosen dalam sistem.

\begin{tabular}{|c|c|c|c|c|c|c|}
\hline \multicolumn{5}{|c|}{ Penjadwalan Matakuliah } & \multicolumn{2}{|c|}{ I admin | Logout } \\
\hline i: Profil ADUN & \multicolumn{6}{|c|}{ Modul Dosen } \\
\hline 2. Data Login & \multicolumn{6}{|c|}{ Beranta Whodu Dosen } \\
\hline Data & \multicolumn{2}{|l|}{ Nama } & Cari Clear & & \multicolumn{2}{|c|}{ + Konten Bar } \\
\hline \multicolumn{7}{|l|}{ L Kaprodi } \\
\hline \multicolumn{7}{|l|}{2 oosen } \\
\hline Matathulah & No & NIDN & Nama & Telp & Status & \\
\hline e Program Studi & 01 & 0127892431 & Afni Eliana Saragh, SE, M.Si & 082378542134 & HONORER & $1:$ \\
\hline : Pengampu & 02 & 0108117501 & Andy Paul Haranang, ST, MKom & 081245327845 & PEGANAI TETAP & $1:$ \\
\hline A Ruang & 03 & 0111067801 & Desinta Purda, ST, M Kom & 081325672134 & PEGANAI TETAP & $1:$ \\
\hline 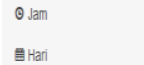 & 04 & 0114344231 & De FriezR Tambunan & 081314543789 & PEGANAA TETAP & 11 \\
\hline O Weaktu Tidak Bersedfa & 05 & 0114046501 & De Zzakarasas Stitumorang & 081223456213 & PEGANAA TETAP & $1:$ \\
\hline Proses & $\infty 6$ & 0225679321 & Dra. Anita Tramarbunan, M.Si & 085278943124 & PEGANA TETAP & $1:$ \\
\hline E Penjadualan & 07 & 0124126801 & Drs. Lamhot Sitorus, M.Kom & 081232457547 & PEGANAA TETAP & 11 \\
\hline Kulah Pengganti & 08 & 0112345798 & Drs. Losten Tamba, MPd & 081234216879 & PEGAMAN TETAP & 1 \\
\hline
\end{tabular}

Gambar 6 berikut adalah menu mata kuliah. Menu ini dapat digunakan admin untuk memanipulasi dan menginput data mata kuliah dalam sistem.

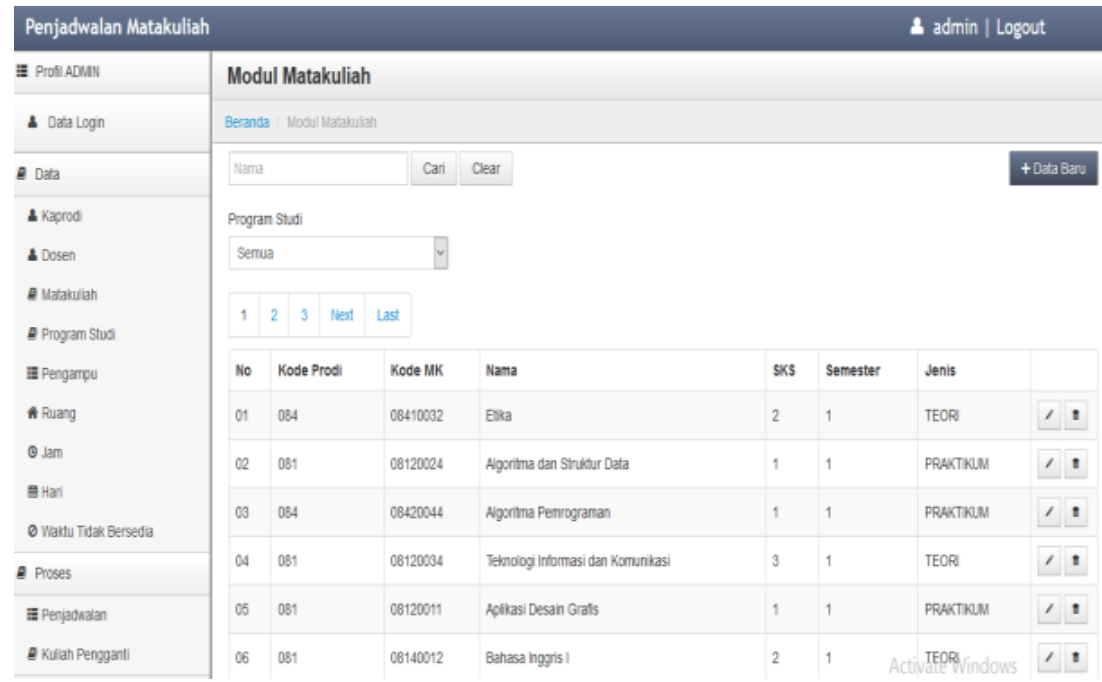

Gambar 6 Menu Mata Kuliah 
Gambar 7 berikut adalah menu pengampu. Menu ini berisi pengampu setiap mata kuliah, kelas, jumlah mahasiswa, dan tahun akademik dalam mata kuliah tersebut.

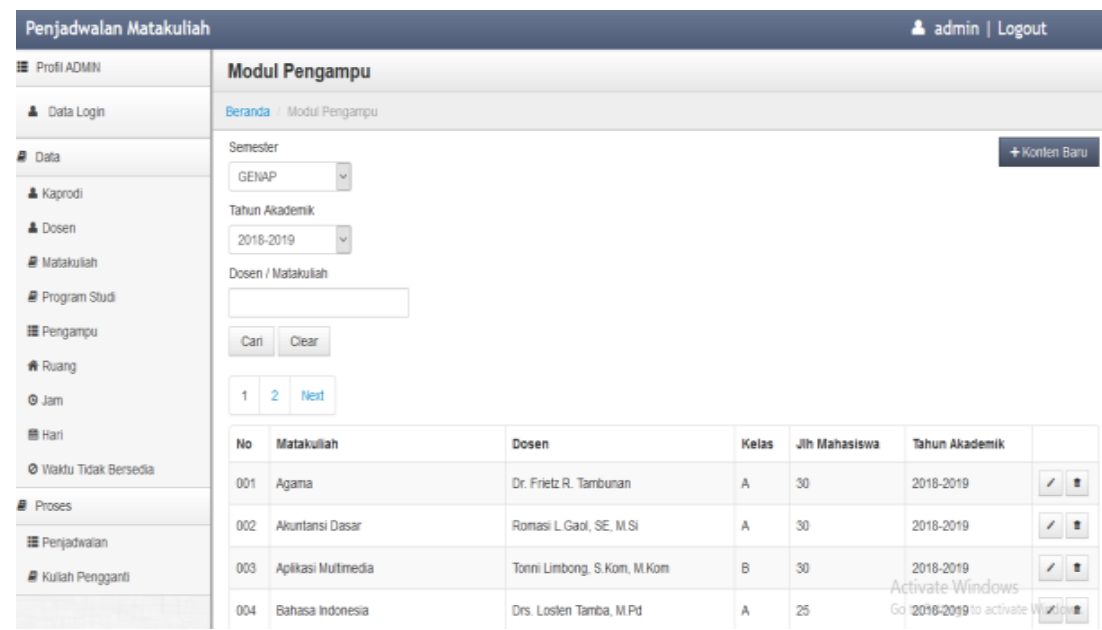

Gambar 7 Menu Pengampu

Gambar 8 berikut adalah menu waktu tidak bersedia. Menu ini digunakan admin untuk memanipulasi waktu tidak bersedia dosen dalam sistem.

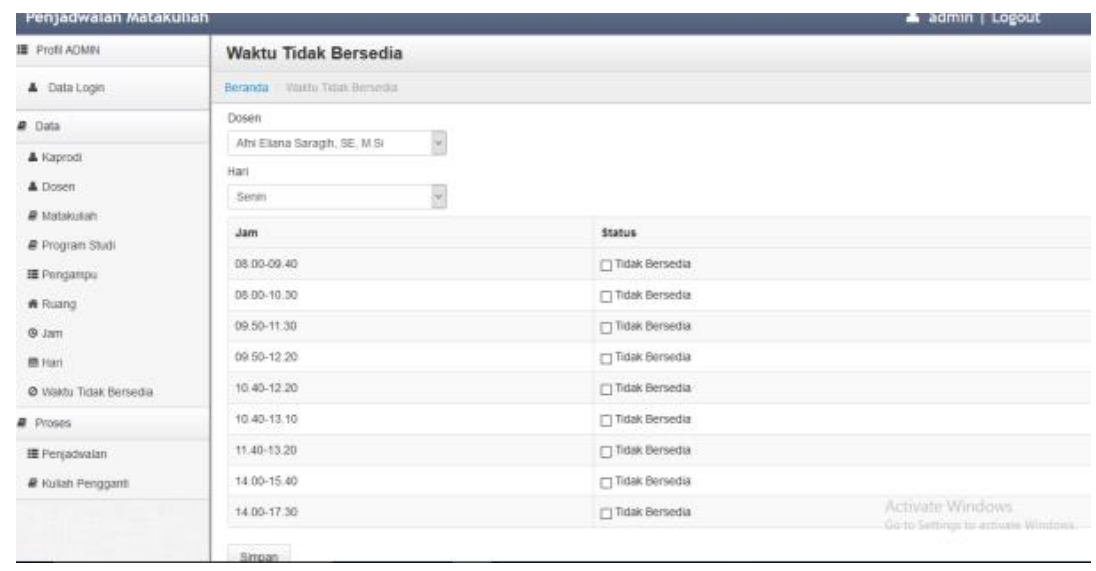

Gambar 8 Menu Waktu Tidak Bersedia

Gambar 9 berikut adalah menu penjadwal an. Menu ini dapat digunakan admin untuk membuat jadwal perkuliahan dalam sistem.

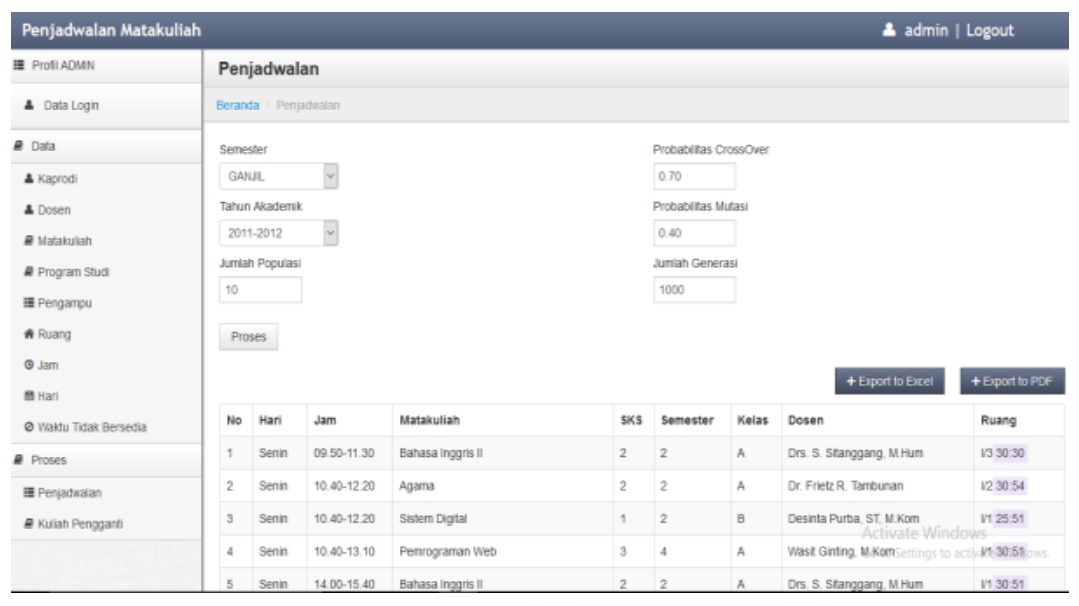

Gambar 9 Menu Penjadwalan 
Gambar 10 berikut adalah menu kuliah pengganti. Menu ini dapat digunakan admin untuk memanipulasi jadwal kuliah pengganti dalam sistem.

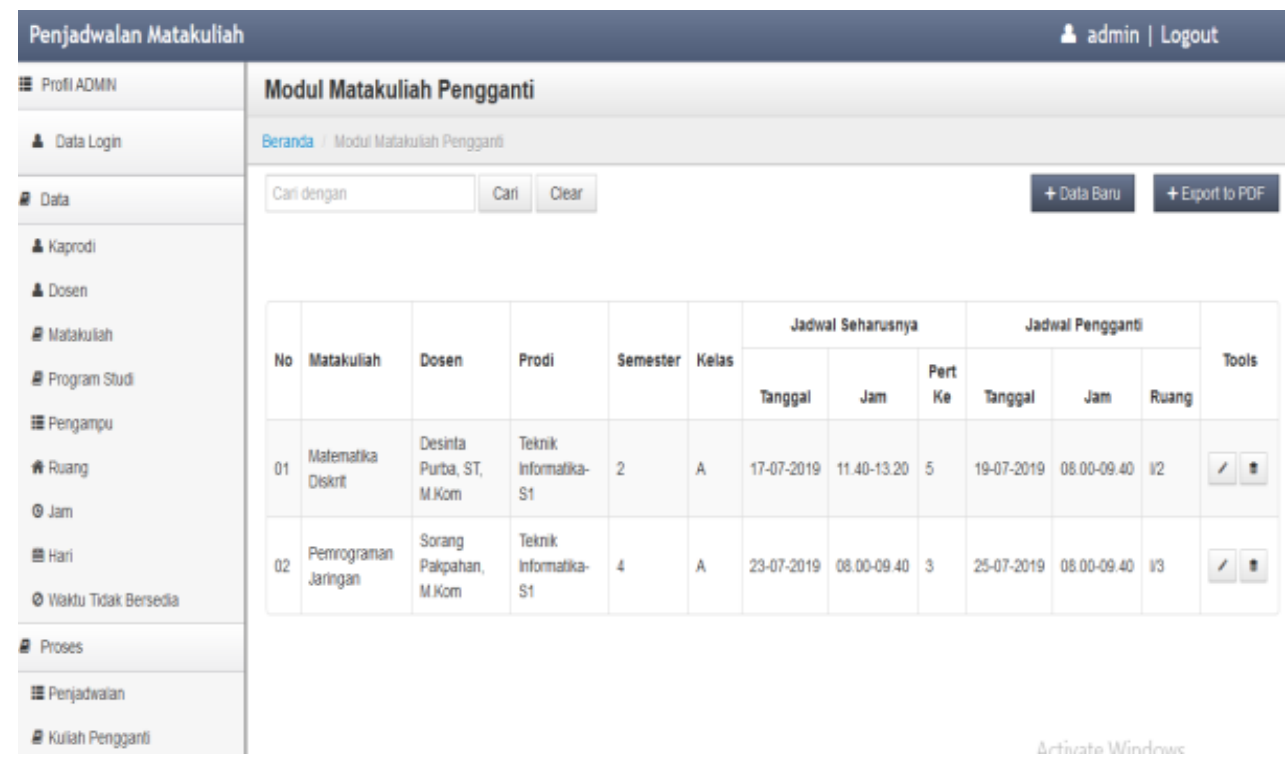

Gambar 10 Menu Kuliah Pengganti

Tampilan output jadwal mata kuliah seperti pada gambar 11 berikut.

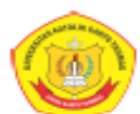

JADWAL KULIAH SEMESTER GANJIL T.A 2018/2019

FAKULTAS ILMU KOMPUTER

UNIVERSITAS KATOLIK SANTO THOMAS SU

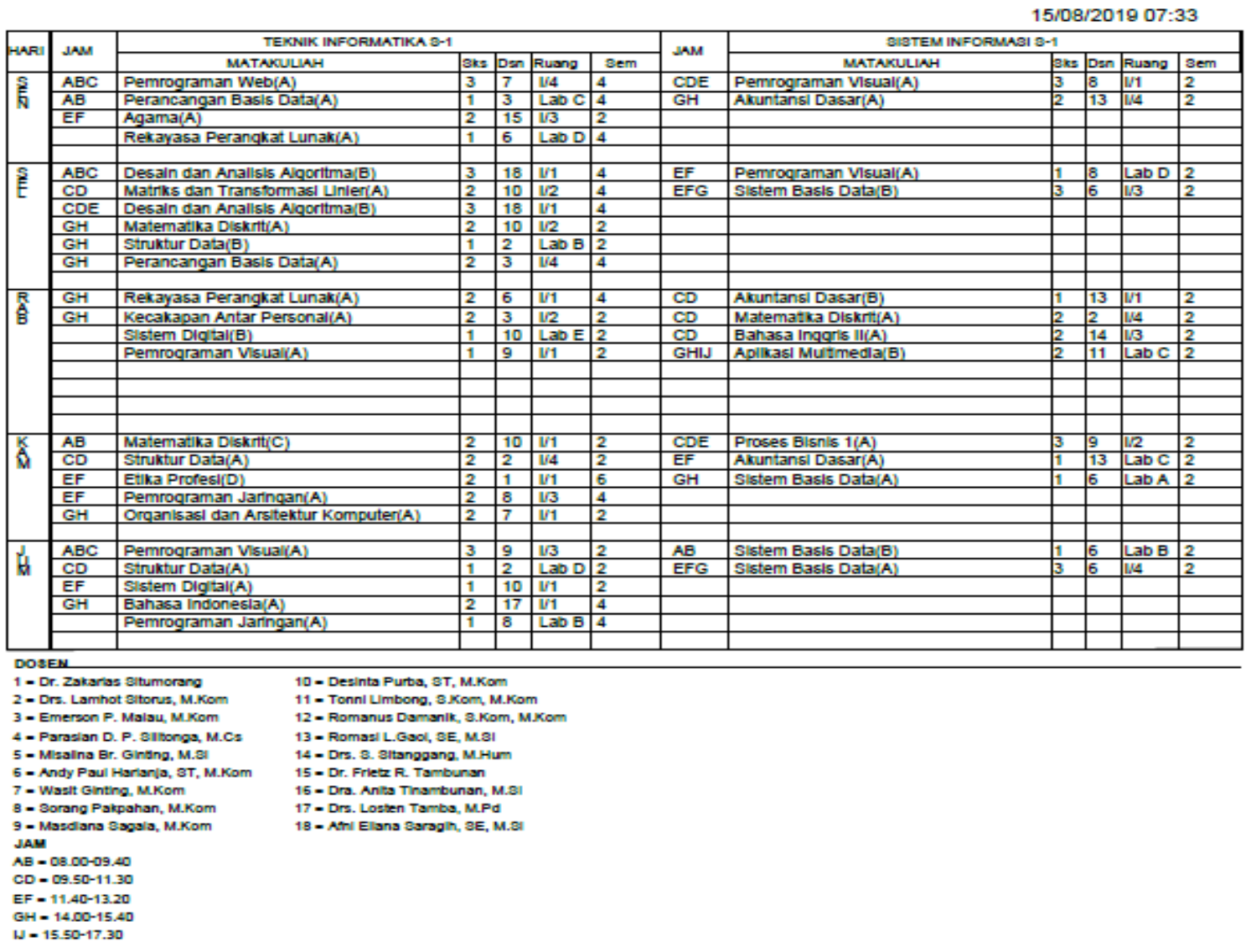

Gambar 11 Jadwal Matakuliah 
Tampilan output jadwal kuliah pengganti seperti pada gambar 12 berikut.

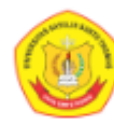

JADWAL KULIAH PENGGANTI

UNIVER SITAS KATOLIK SANTO THOMAS SU

TEKNIK INFORMATIKA-S1 \& SISTEM INFORMASI-S1

22/07/2019 03:56

\begin{tabular}{|c|c|c|c|c|c|c|c|c|c|c|c|}
\hline \multirow[b]{2}{*}{ NO } & \multirow{2}{*}{ MATAKULIAH } & \multirow[b]{2}{*}{ DSN } & \multirow{2}{*}{ PRODI } & \multirow{2}{*}{ SEM } & \multirow{2}{*}{ KELAS } & \multicolumn{3}{|c|}{ JADWAL SEHARUSNYA } & \multicolumn{3}{|c|}{ JADWALPENGGANTI } \\
\hline & & & & & & TGL & JAM & PERTEMUAN KE- & TGL & JAM & RUANG \\
\hline 1 & Matematika Diskrit(A) & 10 & $\mathrm{Tl}$ & 2 & A & $17 / 07 / 2019$ & $11.40-13.20$ & 5 & 19/07/2019 & $08.00-09.40$ & $1 / 2$ \\
\hline 2 & Pemrograman Jaringan(A) & 8 & $\mathrm{Tl}$ & 4 & A & $23 / 07 / 2019$ & $08.00-09.40$ & 3 & $25 / 07 / 2019$ & $08.00-09.40$ & $1 / 3$ \\
\hline
\end{tabular}

$1=$ Dr. Zakaras Stumorang

$2=$ Drs. Lamhot S7arus, M.Kom

3 - Emerson P. Masiau, M.Kom

4 = Parasian D. P. Sutonga, M.C.

5 = Masilina Br. Gintng. M.Si

6 - Anoly Paul Harianja, ST, M.Kor
7 - Wasst Ginting, M.Kom

$7=$ Wassil Ginting, M.Kom
$B=$ Scrang Paipahon, M.Kon

$11=$ Tonni Limbong, S.Kom, M.Kom

$12=$ Romanus Damanik, S.Kom, M.Kon

13 - Romasi L Gaol, SE, M.Si

$14=$ Drs. S. Stangang, M.HU

$15=$ Dr. Frictz $R$. Tambunan

16 - Dra. Anita Tinambunan, MS

$18=$ Atri Elans Saragh SE, M.S

= Maadiana Sagala, M.Kam

10-Desinta Puthe ST, MKom

Gambar 12 Jadwal Kuliah Pengganti

\section{KESIMPULAN}

Adapun kesimpulan dari penelitian ini yaitu:

1. Algoritma genetika merupakan proses pencarian yang heuristik dan acak sehingga penekanan pemilihan operator yang digunakan sangat menentukan keberhasilan algoritma genetika dalam menemukan solusi optimum suatu masalah yang diberikan.

2. Dengan adanya sistem penjadwalan perkuliahan proses penjadwalan perkuliahan dapat dilakukan dengan lebih efisien.

3. Berdasarkan pengujian data yang telah dilakukan, jadwal yang diinginkan (tidak bentrok) dapat diperoleh dengan jumlah iterasi sebanyak 1 sampai 10 kali.

\section{DAFTAR PUSTAKA}

[1] M. Destiningrum and Q. J. Adrian, "Sistem Informasi Penjadwalan Dokter Berbassis Web Dengan Menggunakan Framework Codeigniter (Studi Kasus: Rumah Sakit Yukum Medical Centre)," J. Teknoinfo, vol. 11, no. 2, p. 30, 2017, doi: $10.33365 /$ jti.v11i2.24.

[2] O. Laoly and T. Limbong, "Visualisasi Pengumuman dan SOP Fakultas Ilmu Komputer Universitas Katolik Santo Thomas Medan berbasis Multimedia," MEANS (Media Inf. Anal. dan Sist., vol. 3, no. 2, pp. 126-139, Dec. 2018, doi: 10.17605/JMEANS.V3I2.276.

[3] W. A. Puspaningrum, A. Djunaidy, and R. A. Vinarti, "Penjadwalan Mata Kuliah Menggunakan Algoritma Genetika di Jurusan Sistem Informasi ITS," J. Tek. POMITS, vol. 2, no. 1, pp. 127-131, 2013.

[4] Muliadi, "Pemodelan Algoritma Genetika," Pemodelan Algoritm. Genet. Pada Sist. Penjadwalan Perkuliahan Prodi Ilmu Komput. Univ. Lambungmangkurat, vol. 01, no. 01, pp. 67-78, 2014.

[5] A. N. Toscany and R. Roestam, "Pengembangan Sistem Penjadwalan Kuliah Menggunakan Algoritma Genetik (Studi Kasus : Pascasarjana Universitas Jambi),” J. Manaj. Sist. Inf., vol. 2, no. 2, pp. 379-393, 2017.

[6] R. S. Wahono, "Penerapan Algoritma Genetika untuk Optimasi Parameter pada Support Vector Machine untuk Meningkatkan Prediksi Pemasaran Langsung," J. Intell. Syst., vol. 1, no. 2, pp. 115-119, 2015.

[7] A. Josi, "Implementasi Algoritma Genetika Pada Aplikasi Penjadwalan Perkuliahan Berbasis Web Dengan Mengadopsi Model Waterfall," J. Inform. J. Pengemb. IT, vol. 02, no. 02, pp. 77-83, 2017, doi: 10.30591/JPIT.V2I2.517.G554.

[8] E. Sugiarto, S. Winarno, and A. Fahmi, "Penjadwalan Perkuliahan Otomatis Berbasis Fuzzy Logic Dan Genetic Algorithm," Techno.COM, vol. 14, no. 4, pp. 315-328, 2015.

[9] T. Limbong and P. D. P. Silitonga, "LOCAL DEVELOPMENT APPLICATION OF LEARNING CONTENT-BASED MULTIMEDIA BATAK TOBA SCRIPTS,” AISTELL Univ. Negeri Medan, vol. 1, no. 1, pp. 544-551, 2016. 